\title{
Hot-Cracking of High-Alloyed Steels Evaluated by Wedge Rolling Test
}

\author{
I. Schindler ${ }^{1, a}$ P. Suchánek, ${ }^{1}$ S. Rusz, ${ }^{1}$ P. Kubečka, ${ }^{1}$ J. Sojka, ${ }^{1}$ M. Heger, ${ }^{1}$ \\ M. Liška, ${ }^{2, b}$ and M. Hlisníkovskýy ${ }^{3, c}$
}

1 VŠB - Technical University of Ostrava, Ostrava, Czech Republic

${ }^{2}$ VITKOVICE - Research \& Development, Ltd., Ostrava, Czech Republic

${ }^{3}$ TŘINECKÉ ŽELEZÁRNY, a.s., Trinec-Staré Mềsto, Czech Republic

a ivo.schindler@vsb.cz, ${ }^{\mathrm{b}}$ miroslav.liska@vitkovice-vyzkum.cz, ${ }^{\mathrm{c}}$ marek.hlisnikovsky@trz.cz

We present a new methodology of determination of hot-cracking of metallic materials, which is based on laboratory application of the wedge rolling test and computer processing of the results obtained. The experiment was made with selected new types of high-alloyed free-cutting (ferritic and austenitic) steels. The initial specimens underwent an additional modification enabling easier development of cracks which consisted in milling out of the defined $V$-shaped notches on a side wall of a specimen. After taking specimens from the rolled material, we performed the metallographic analysis of microstructures by means of optical microscopy as well as a SEM analysis of the cracks. The resulting microstructure in the propagating crack vicinity was markedly influenced by this fracture. In the crack vicinity, a noticeable refinement of grains was observed due to the stress-induced recrystallization and occurrence of deformation zones that were pronounced by the rolled-out and stretched sulphides. As a rule, fractures were created by the ductile failure with visible pits, caused by tearing of sulphides from the material. Susceptibility of the studied steels to hot-cracking was evaluated and compared.

Keywords: hot-cracking, wedge rolling test, free-cutting stainless steel, microstructure.

Introduction. Based on the long-term research of plastic properties of metallic materials, a new methodology of hot formability was developed on the basis of wedge rolling test realized in laboratory conditions of the Institute of Modeling and Control of Forming Processes at VЉB-TU Ostrava [1]. A simple laboratory test performed by rolling of the wedge-shaped specimen on plain rolls provides a possibility of effective investigation of hot deformation behavior of metallic materials, due to implementation of a wide range of height reductions in a single specimen. The wedge rolling test is suitable for fast evaluation of formability as well as, in combination with subsequent metallographic analyses, for study of selected structural processes. Similarity of laboratory and industrial rolling provides conditions for the appropriate quantitative comparison and application of results in practice.

Laboratory Hot Rolling Conditions. The experiment was made with two selected types of high-alloyed free-cutting stainless steels - the ferritic steel 17043STiMod (with $0.05 \mathrm{C}, 0.30 \mathrm{Mn}, 0.12 \mathrm{Si}, 0.50 \mathrm{~S}, 16.4 \mathrm{Cr}, 0.34 \mathrm{Ti}$ in wt.\%) and the austenitic steel 17247SCuTi $(0.04 \mathrm{C}, 0.23 \mathrm{Mn}, 0.14 \mathrm{Si}, 0.20 \mathrm{~S}, 1.41 \mathrm{Cu}, 8.9 \mathrm{Ni}, 17.0 \mathrm{Cr}, 0.41 \mathrm{Ti})$. Initial wedge specimens with trapezoid shape have the following dimensions: width $15 \mathrm{~mm}$, minimum thickness $3 \mathrm{~mm}$, length 94-150 mm (depending on the predicted rolling forces), and angle $4^{\circ} 34^{\prime}$. They underwent an additional modification enabling easier development of cracks which consisted in milling out of the defined V-shaped notches on a side wall of the specimen. The single-pass rolling of specimens in the laboratory mill stand K350 was used, after heating directly to the forming temperature (i.e., $800-1100^{\circ} \mathrm{C}$ for the ferritic steel, and $800-1250^{\circ} \mathrm{C}$ for the austenitic steel). The rolls with diameter of $140 \mathrm{~mm}$ rotated at nominal speed of $110 \mathrm{~min}^{-1}$, final thickness of the rolled specimens was $3.2 \mathrm{~mm}$ on average.

(c) I. SCHINDLER, P. SUCHÁNEK, S. RUSZ, P. KUBEĈ̃KA, J. SOJKA, M. HEGER, M. LIŜ̃KA, M. HLISNIKOVSKÝ, 2008 
Immediately after rolling, each specimen was cooled down in a water bath with the aim of fixing of the structure. Its plan was scanned to the form of bit maps which enabled calculation of deformation and speed relations along the length of the rolled product [2] The program KLIN [1] has been specially developed on the basis of computer image analysis and gradual comparison of the total and partial volumes of the initial specimen and the rolled product. The main advantage of the above program is that it can operate with arbitrary irregular plan shape of the rolled product and take into account the influence of uneven spread and changing thickness along the rolled product in the calculation. Figure 1 illustrates the shape of the selected rolled specimen as well as the calculated quantities.

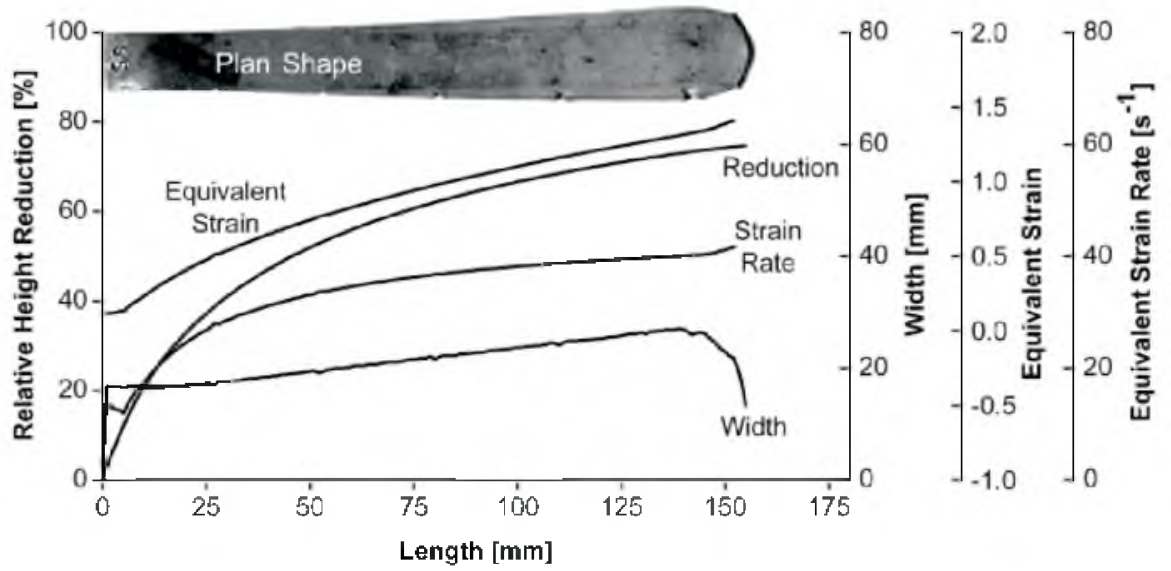

Fig. 1. Plan shape of the rolled out wedge and strain/speed relations along the rolling stock (austenitic steel, temperature $900^{\circ} \mathrm{C}$ ).

Processing of Experimental Data. In case of the rolled products from the austenitic steel, larger elongation can be observed, as compared to those from the ferritic steel, whereas the latter exhibited larger spread. The steel $17247 \mathrm{SCuTi}$ was characterized by relatively poor plastic properties - cracks occurred even at the highest forming temperature $T=1250^{\circ} \mathrm{C}$. With decreasing rolling temperature frequency of cracks raised, which is shown in Table 1 summarizing the achieved results and Fig. 2a.

$\mathrm{T}$ a b 1 e 1

Occurrence of Cracks in Particular Rolled Out Specimens near Notches V1 to V8

\begin{tabular}{|c|c|c|c|c|c|c|c|c|c|}
\hline Steel grade & $T,{ }^{\circ} \mathrm{C}$ & V1 & $\mathrm{V} 2$ & V3 & V4 & V5 & V6 & V7 & V8 \\
\hline 17043STiMod & $\begin{array}{c}1100 \\
1000 \\
900 \\
800\end{array}$ & & & & $x$ & $\begin{array}{l}\times \\
\times \\
\times \\
\end{array}$ & $\begin{array}{l}x \\
\times \\
0\end{array}$ & $\begin{array}{l}\times \\
0 \\
0\end{array}$ & $\begin{array}{l}\times \\
0 \\
0\end{array}$ \\
\hline $17247 \mathrm{SCuTi}$ & $\begin{array}{c}1250 \\
1200 \\
1100 \\
1000 \\
900 \\
800\end{array}$ & & & $\begin{array}{l}x \\
\times \\
\times\end{array}$ & $\begin{array}{l}x \\
x \\
x \\
x\end{array}$ & $\begin{array}{c}\times \\
\times \\
\times \\
\times \\
\times\end{array}$ & $\begin{array}{l}x \\
\times \\
\times \\
\times \\
\times \\
0\end{array}$ & $\begin{array}{l}\times \\
\times \\
\times \\
\times \\
0 \\
0\end{array}$ & $\begin{array}{l}x \\
\times \\
\times \\
\times \\
0 \\
0\end{array}$ \\
\hline
\end{tabular}

Note: $X=$ an evident crack; $O=$ absence of notch due to necessary shortening of the specimen. 


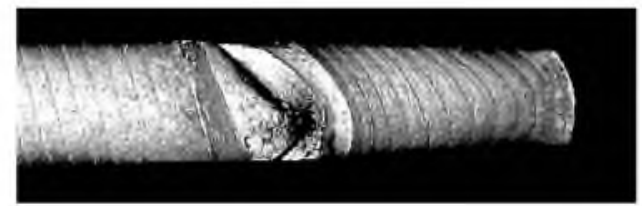

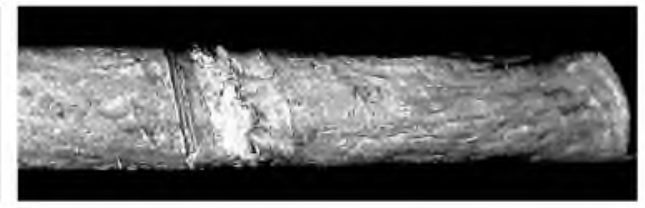

b

Fig. 2. Details of cracks after rolling of selected specimens: (a) austenitic steel rolled at $900^{\circ} \mathrm{C}-$ notch V6; (b) ferritic steel rolled at $800^{\circ} \mathrm{C}-$ notch V5.

The steel 17043 STiMod was characterized by much better plastic properties (Fig. 2b). No cracks developed even at the highest forming temperature $1100^{\circ} \mathrm{C}$. With decreasing forming temperature the number of cracks initiated in the area of notches increased, but differences observed at forming temperatures 800 to $1000^{\circ} \mathrm{C}$ are by no means considerable. The flow of the material spread, appearance of side surfaces and character of cracks are very different as compared with the investigated austenitic steel.

Structural and Fracture Analysis. Micrographs in Fig. 3 demonstrate shapes of selected cracks under notches that were subjected to the largest deformation. Structure of the specimens from steel 17043STiMod (Fig. 3a) is created purely by ferrite with separated sulphidic inclusions. It is very probable that the main cracks were developed under the material surface: they did not ascend to surface in the notch area. In the vicinity of the crack, refinement of the structure is observed due to a higher deformation and stress-induced recrystallization. The developed fractures were controlled by a mixed (transcrystalline and intercrystalline) ductile fracture mechanism, which is illustrated by Fig. $4 \mathrm{a}, \mathrm{b}$ (rolling at $1000^{\circ} \mathrm{C}$ ). Specimens from steel $17247 \mathrm{SCuTi}$ have an austenitic structure with very high occurrence of large sulphidic inclusions. Evident deformation zones are visible in the surroundings of the propagating crack, pronounced by deformed and elongated sulphides (Fig. 3b). Fine cracks, perpendicular to the axis of the main crack, occur again. The crack started obviously from the surface of the rolled product but with proceeding deformation it was closed by influence of the material flow. The cracks were created by a ductile fracture mechanism with large occurrence of pits caused by tearing of sulphides from the material - see Fig. $4 \mathrm{c}$, d (rolling at $800^{\circ} \mathrm{C}$ ).

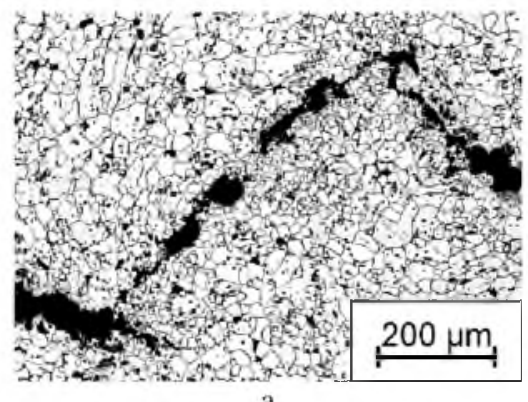

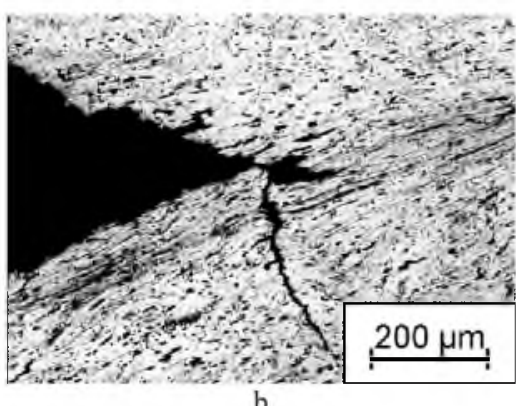

Fig. 3. Metallographic photographs of cracks under last notches (the largest height reduction): (a) ferritic steel rolled at $1000^{\circ} \mathrm{C}$; (b) austenitic steel rolled at $800^{\circ} \mathrm{C}$.

Conclusions. In this study of formability, the results of conventional plastometric (e.g., torsion [3]) experiments exhibited high response of the studied material to varying thermomechanical conditions of forming, but have often been burdened with data scattering (mainly due to premature fracture of small specimens containing relatively large defects). The wedge rolling test gives the results that can be evaluated in a more difficult way and, in addition to that, it is suitable only for materials with impaired plasticity. In the 

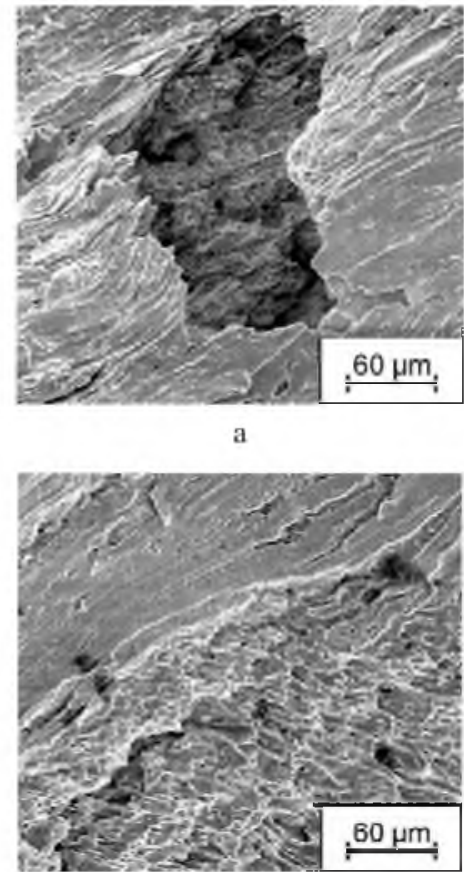

c

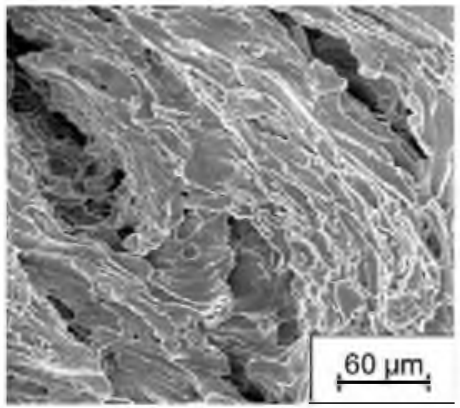

b

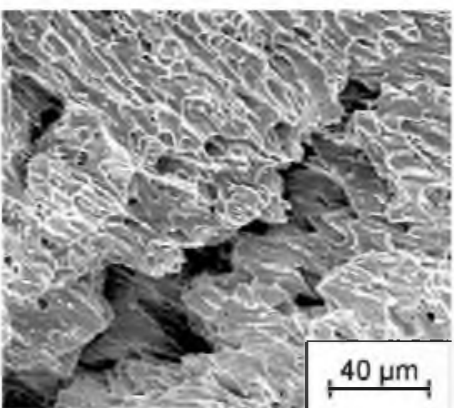

d

Fig. 4. Photographs from SEM - view of cracks under last notches (the largest height reduction).

case of most steel grades, it is necessary to improve its sensitivity by the milled notches, which function like initiators of cracks in spreading parts of the rolled product.

As far as rollability is concerned (which is evaluated by a number of cracks, their shape and location in the rolled products), it can be concluded that, in comparison with similar tests performed with other types of steel, reduced formability was observed for both free-cutting steels with sulphur, notwithstanding some differences in their deformation behavior. The specimens from the ferritic steel 17043STiMod had better plastic properties in comparison to the austenitic steel $17247 \mathrm{SCuTi}$.

In the crack surroundings, a refinement of the structure was observed due to the stress-induced recrystallization and occurrence of deformation zones that were pronounced by the rolled-out and stretched sulphides. As a rule, fractures were created by a tough failure with visible pits, caused by tearing of sulphides from the material containing high level of detrimental sulphur.

Acknowledgments. The methodology of wedge rolling test has been developed under the Research Plan MSM6198910015 (Ministry of Education of the Czech Republic). The tested materials have been obtained in the framework of solution of the Project Impuls FI-IM 2/043 (Ministry of Industry of the Czech Republic).

1. M. Heger, I. Schindler, J. Franz, and K. Čmiel, in: CO-MAT-TECH 2003, STU Bratislava (2003), p. 255.

2. P. Suchánek, I. Schindler, P. Turoñová, et al., in: Steel Strip 2006, Steel Strip Society (2006). p. 349.

3. I. Schindler and J. Bor̆uta, Utilization Potentialities of the Torsion Plastometer, PS Katowice. Poland (1998). 